\title{
Credit risk Measurement of Commercial Banks in China at the present stage
}

\author{
Jiabin Li, Lei Zhang*, Changzhe Deng \\ Pan-Asian Business School, Yunnan Normal University, Yunnan, China \\ *bookdoglee@163.com \\ 现阶段我国商业银行信用风险度量 \\ 李佳涁, 张雷*, 邓长哲 \\ 云南师范大学泛亚商学院, 云南昆明 650092 , 中国 \\ *bookdoglee@163.com
}

\begin{abstract}
Taking 25 commercial banks in 2018 as data samples, this paper uses $\mathrm{kmv}$ model to measure their credit risk, and evaluates 25 commercial banks in $S \& P$, Moody's rating default probability mapping relationship. The results show that in mid-2018, the credit risk of 25 commercial banks is measured by means of the standard \& poor's, Moody's and Moody's rating probability. Most of the 25 commercial banks have lower credit risk; Wuxi Bank exposed a large risk position; Hangzhou Bank second. Beijing, China, Xingye, Jiangsu, Pufa, Transportation, Industry and Commerce, Agriculture, Merchants, Construction, CITIC, Everbright, Sunong, Nanjing, Ningbo, Minsheng, Changshu, Ping an, Jiangyin, Guiyang Bank Standard \& Poor's rating $\geqslant$ aa, Moody's rating $\geqslant$ aa2; China, Zhangjiagang, Bank of Shanghai Standard \& Poor's rating is aa/a, Moody's rating is A1; Hangzhou Bank's Standard \& Poor's rating is a/bbb; Moody's rating is baa1; Wuxi Bank Standard \& Poor's rating is bbb-/bb, Moody's rating is ba1.
\end{abstract}

\section{Keywords-Credit Risk; KMV; Commercial Bank}

摘要一文章以 2018 年 25 家商业银行为数据样本, 利用 KMV 模型度量其信用风险, 并在标准普尔、穆迪评级违约概率 的映射关系对 25 家商业银行进行评级, 结果表明: 在 2018 年中, 25 家商业银行大部分风险较低; 无锡银行暴露的风险 头寸较大; 杭州银行其次。北京、中国、兴业、江苏、浦发、 交通、工商、农业、招商、建设、中信、光大、苏农、南京、 宁波、民生、常熟、平安、江阴、贵阳银行标准普尔评级为 $\mathrm{AA}$, 穆迪评级为 $\mathrm{Aa} 2$; 华夏、张家港、上海银行标准普尔评级 为 $\mathrm{AA} / \mathrm{A}$, 穆迪评级为 $\mathrm{A} 1$; 杭州银行标准普尔评级为 $\mathrm{A} / \mathrm{BBB}+$, 穆迪评级为 $\mathrm{Baa} 1$; 无锡银行标准普尔等级为 $\mathrm{BBB}-/ \mathrm{BB}$, 穆迪 评级为 $\mathrm{Ba} 1$ 。

关键词一信用风险; KMV; 商业银行

$$
\text { I.引言 }
$$

关于信用一词，俗语有云：“人而无信，不知其可 也”，“民无信不立”，历史先辈们对信用在社会的意 义已经有了很深刻的认识。随着我国金融市场逐渐发展 走向成熟，信用风险也暗含其中，信用风险所造成的影 响从 2008 年次贷危机机中可见一斑, 因此对于信用风险 度量、防范与管理对于社会、对于国家、对于企业以及 对于个人都是一件百利而无一害的事情。运用 KMV 度
量信用风险优点在于它是建立在现代公司财务理论和期 权理论基础上的一种信用监测模型, 拥有很强的理论基 础, 具有说服力。

随着我国金融市场不断深化, 商业银行在金融市场 一直扮演着重要的角色, 并且信用风险是商业银行的主 要风险。根据银保监会的数据, 2018 年银行业不良贷款 率为 $1.89 \%$, 较 2016 年、2017 年 $1.74 \%$ 的商业银行不良 贷款率上升 0.15 个百分点。伴随着我国经济减速追求质 量的发展，商业银行是否在 2018 年暴露较大的风险头寸, 我们能否有效管理和防范商业银行的信用风险是具有意 义。本文在总结学者对于 KMV 模型进行改进方法基础 下, 对 2018 年 25 家商业银行的信用风险进行度量, 并 在标准普尔、穆迪评级与违约概率的映射关系下对 25 家 商业银行进行评级。

\section{II.文献回顾}

所谓信用风险, 是指债务人或者交易对手未能履行 合约规定的义务或因信用质量发生变化导致金融工具价 值发生变化, 给债券人或金融工具持有人带来损失的风 险。关于运用 KMV 模型度量信用风险研究, 主要涉及 到以下三方面:其一对 $\mathrm{KMV}$ 模型的改进, 其中主要包括 参数指标的改进, 如刘向华和李林娜 [1]引入 GARCH$\mathrm{KMV}$ 模型求解单个资产的违约概率, 并进一步利用 $\mathrm{t}-$ Copula 函数对标的资产的违约相关性进行建模, 对存款证 进行定价; 蒋书涁错误! 未找到引用源。考量在不同的 $\mathrm{KMV}$ 模型违约距离下对商业银行的信用风险进行度量; 谢赤和王彭[3]将 DCC-MSV 与 KMV 模型相结合，构造 信用风险传染模型考察第三行业的信用风险的传染效益; 王秀国和谢幽筀[4]提出了 $\mathrm{CVaR}$ 和 $\operatorname{GARCH}(1,1)$ 的扩展 KMV 模型并对沪市上市公司进行实证检验; 李杰汀 [5] 利用传染模型对企业内部的信用风险进行度量; 其二研 究对象不同, 其中主要包括上市公司、银行、地方债务 以及债券, 如徐蕾, 刘小川[6]以及徐占东和王雪标[7]通 过建模构建地方政府债务违约概率测算模型; 李晟, 张宇 航[8]利用修正的 KMV 模型度量商业银行的信用风险; 张玲, 杨贞柿 [9]、蒋战, 高瑜 [10]以及唐振鹏,陈尾虹[11]对 上市公司的信用风险进行评估; 曾诗鸿和王芳[12]使用 ST 和*ST 公司的财务数据对违约点进行修正, 并对制造 
业 42 家公司进行实证检验; 徐朝辉[13]通过税制改革的 角度对公司的信用风险进行研究; 其三由于传统的 KMV 模型对上市公司进行信用风险度量, 有些学者利 用扩展 KMV 模型对非上市公司的信用风险进行实证分 析，如戴志锋和张宗益[14]利用穆迪公司旗下的 KMV 公 司开发针对非上市公司信用风险度量模型对中国上市公 司数据和某国有商业银行非上市公司的信贷数据进行信 用风险度量，并对非上市公司模型在中国的适用性进行 了实证验证。本文在对学者们对 KMV 参数指标改进基 础上对 2018 年 25 家商业银行的信用风险进行度量, 并 根据标准普尔和穆迪评级标准对其进行评级。

\section{III.模型介绍与指标选取}

\section{(1) KMV 模型介绍}

KMV 模型以期权定价理论为理论基础, 于 1997 年 由 KMV 公司推出度量信用风险的预测模型。

假设公司在 $\mathrm{t}$ 时刻的负债价值为 $\mathrm{F}$, 公司资产价值在 风险中性概率测度下服从几何布朗运动:

$$
\mathrm{dV}_{\mathrm{t}}=\mathrm{rV}_{\mathrm{t}} \mathrm{dt}+\delta_{\mathrm{v}} \mathrm{V}_{\mathrm{t}} \mathrm{dW}_{\mathrm{t}}
$$

根据 Black-Scholes 期权定价模型，如果在 $\mathrm{T}$ 时刻, 公司的负债价值为 $\mathrm{F}$, 那么现在的公司股票市值 $\mathrm{S}_{\mathrm{t}}$ 和公 司资产价值 $\mathrm{V}_{\mathrm{t}}$ 之间的关系为:

$$
\mathrm{S}_{\mathrm{t}}=\mathrm{V}_{\mathrm{t}} \mathrm{N}\left(\mathrm{d}_{1}\right)-\mathrm{Fe}^{-\mathrm{r}(\mathrm{T}-\mathrm{t})} \mathrm{N}\left(\mathrm{d}_{2}\right)
$$

其中, $\mathrm{r}$ 是无风险利率, $\mathrm{d}_{1}=\frac{\ln \frac{\mathrm{V}_{\mathrm{t}}}{\mathrm{F}}+\left(\mathrm{r}+\frac{\delta^{2}}{2}\right)(\mathrm{T}-\mathrm{t})}{\delta_{\mathrm{V}} \sqrt{\mathrm{T}-\mathrm{t}}}$, $\mathrm{d}_{2}=\mathrm{d}_{1}-\delta_{\mathrm{V}} \sqrt{\mathrm{T}-\mathrm{t}}$

(2) 式中的 $V_{t}$ 和 $\delta_{V}$ 都是市场上不能直接观察到的变 量。公司股票收益率的波动性 $\delta_{\mathrm{S}}$ 和公司资产价值收益率 波动性 $\delta_{\mathrm{V}}$ 之间存在关系，具体如下，将（2）式由伊藤 过程得到:

$$
\begin{aligned}
& \mathrm{dS}_{\mathrm{t}}=\mathrm{rS}_{\mathrm{t}} \mathrm{dt}+\delta_{\mathrm{S}} \mathrm{S}_{\mathrm{t}} \mathrm{dW}_{\mathrm{t}}\left(\frac{\partial \mathrm{S}}{\partial \mathrm{t}}+\frac{\partial \mathrm{S}}{\partial \mathrm{V}} \mathrm{rV}_{\mathrm{t}}+\frac{\delta_{\mathrm{v}}^{2}}{2} \mathrm{~V}_{\mathrm{t}}^{2} \frac{\partial^{2} \mathrm{~S}}{\partial \mathrm{V}^{2}}\right) \mathrm{dt} \\
&+ \frac{\partial \mathrm{S}}{\partial \mathrm{V}} \delta_{\mathrm{v}} \mathrm{V}_{\mathrm{t}} \mathrm{dW}_{\mathrm{t}} \\
& \text { 其中 } \frac{\partial \mathrm{S}}{\partial \mathrm{t}}=-\mathrm{rFe} \mathrm{r}^{-\mathrm{r}(\mathrm{T}-\mathrm{t})} \mathrm{N}\left(\mathrm{d}_{2}\right), \frac{\partial \mathrm{S}}{\partial \mathrm{V}}=\mathrm{N}\left(\mathrm{d}_{1}\right), \text { 即 } \\
& \mathrm{dS}_{\mathrm{t}}=\mathrm{rS}_{\mathrm{t}} \mathrm{dt}+\delta_{\mathrm{S}} \mathrm{S}_{\mathrm{t}} \mathrm{dW}_{\mathrm{t}} \\
&=\mathrm{rS}_{\mathrm{t}} \mathrm{dt}+\left(\frac{\mathrm{V}_{\mathrm{t}}}{\mathrm{S}_{\mathrm{t}}} \mathrm{N}\left(\mathrm{d}_{1}\right) \delta_{\mathrm{V}}\right) \mathrm{S}_{\mathrm{t}} \mathrm{dW}_{\mathrm{t}}
\end{aligned}
$$

则, $\delta_{\mathrm{S}}=\frac{\mathrm{v}_{\mathrm{t}}}{\mathrm{S}_{\mathrm{t}}} \mathrm{N}\left(\mathrm{d}_{1}\right) \delta_{\mathrm{V}}$

当公司资产价值低于公司债务的账面价值是，公司 将发生违约，则未来 $\mathrm{t}$ 时刻的违约概率为

$$
\mathrm{P}_{\mathrm{t}}=\operatorname{Prob}\left(\mathrm{V}_{\mathrm{t}} \leq \mathrm{F} \mid \mathrm{V}_{0}\right)=\operatorname{Prob}\left(\ln \mathrm{V}_{\mathrm{t}} \leq \ln \mathrm{F}\right)
$$

又根据伊藤过程得:

$$
\ln V_{\mathrm{t}}=\ln \mathrm{V}_{0}+\left(\mu-\frac{\delta_{\mathrm{V}}^{2}}{2}\right) \mathrm{t}+\delta_{\mathrm{V}} \sqrt{\mathrm{t} \varepsilon}
$$

其中 $\mu$ 为资产回报的期望值； $\varepsilon$ 为公司资产回报变动 的随机因子, 服从标准正态分布。
结合（5）式，（4）式有:

$$
\begin{aligned}
\mathrm{P}_{\mathrm{t}}=\operatorname{Prob}\left(\ln \mathrm{V}_{0}\right. & \left.+\left(\mu-\frac{\delta_{\mathrm{V}}^{2}}{2}\right) \mathrm{t}+\delta_{\mathrm{V}} \sqrt{\mathrm{t} \varepsilon} \leq \ln \mathrm{F}\right) \\
& =\operatorname{Prob}\left(\varepsilon \leq-\frac{\ln \frac{\mathrm{V}_{0}}{\mathrm{~F}}+\left(\mu-\frac{\delta_{\mathrm{v}}{ }^{2}}{2}\right) \mathrm{t}}{\delta_{\mathrm{V}} \sqrt{\mathrm{t}}}\right)
\end{aligned}
$$

根据标准正态分布累计概率分布的性质, 未来 $\mathrm{t}$ 时 刻的违约概率为

$$
\mathrm{P}_{\mathrm{t}}=\mathrm{N}\left(-\frac{\ln \frac{\mathrm{V}}{\mathrm{F}}+\left(\mu-\frac{\delta_{\mathrm{v}}{ }^{2}}{2}\right) \mathrm{t}}{\delta_{\mathrm{V}} \sqrt{\mathrm{t}}}\right)
$$

$\mathrm{KMV}$ 公司根据实证研究结果显示, 大量的违约发生 在短期债务加上 $50 \%$ 的长期债务的水平点上, 即: 违约点 $\mathrm{DPT}=$ 短期负债 $+0.5 *$ 长期负债

违约距离为 $\mathrm{DD}=\frac{\text { 资产预期价值 }- \text { 违约点 }}{\text { 资产价值 } \times \text { 资产价值的标准差 }}=\frac{\mathrm{E}\left(\mathrm{V}_{\mathrm{t}}\right)-\mathrm{F}}{\mathrm{E}\left(\mathrm{V}_{\mathrm{t}}\right) \times \delta_{\mathrm{V}} \times \sqrt{\mathrm{t}}}$, 在 Black-Scholes 期权定价公式假设下,

$$
\mathrm{DD}=\frac{\ln \frac{\mathrm{V}_{0}}{\mathrm{~F}}+\left(\mu-\frac{\delta_{\mathrm{V}}^{2}}{2}\right) \mathrm{t}}{\delta_{\mathrm{V}} \sqrt{\mathrm{t}}}
$$

负债 $\mathrm{F}$ 即为违约点 DPT。

\section{(2) 度量指标参数设定}

1. 本文研究样本选择为我国 25 家上市的商业银行, 其中包括工商、农业、建设、中国、交通 5 家国有商业 银行; 招商、浦发、中信、光大、华夏、民生、兴业、 平安 8 家股份制商业银行; 无锡、杭州、上海、张家港、 贵阳、江阴、常熟、宁波、南京、吴江、江苏、北京 12 家城市商业银行。本文选择时间跨度为 2018 年, 其中股 票数据来源于广发证券金融终端数据, 公司股本结构来 自于新浪财经, 公司资产负债数据来源于网易财经, 港 元兑换人民币汇率来自于国家统计局。

\section{2.无风险利率}

无风险利率选取中国人民银行 2018 年一年定期存款 利率 $1.5 \%$ 。

\section{3.违约点确定}

KMV 公司在大量的实证结果显示, 违约点 $\mathrm{DPT}=$ 短 期负债 $+0.5 *$ 长期负债, 本文也沿用 $\mathrm{KMV}$ 公司的使用方 法。

\section{4.股权市场价值}

由于股票市场的价格能够反应上市公司的基本状况， 大多数学者一般选取股票的市场价值作为上市公司的股 权价值, 本文也利用上市公司股票的市场价值估计其股 权市场价值。在所研究的商业银行中有包含大量的限售 股以及高管股, 多数学者如（蒋或[10]，2015 等）所采 取利用每股净资产衡量非流通股的价格, 本文也沿用这 一方法。

商业银行的股票有流通股和非流通股, 其中流通股 有 $\mathrm{A}$ 股与 $\mathrm{H}$ 股, 非流通股有限售股和高管股。因此上市 公司的股权价值 $\mathrm{S}=\mathrm{A}$ 股股票流通数量 $\times \mathrm{A}$ 股股票的价值 $+\mathrm{H}$ 股股票流通数量 $\times \mathrm{H}$ 股股票的价值 $\times$ 港元兑换人民币 的汇率 + 非流通股票的数量 $\times$ 每股净资产。 


\section{5.股权市场价值的波动率}

本文采取(韩娇[15]，2018)所使用的历史波动率法来 计算股权价值的波动率。对于有流通 $\mathrm{A}$ 股和 $\mathrm{H}$ 股的公司, 首先分别对 $\mathrm{A}$ 股和 $\mathrm{H}$ 股股票当天收盘价除以前一天股票

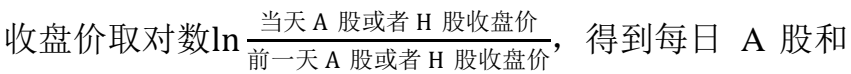
$\mathrm{H}$ 股股价的收益率，然后在计算其在一年的样本标准差， 即为 $\mathrm{A}$ 股和 $\mathrm{H}$ 股一年的股价收益率的波动率。之后将 $\mathrm{A}$ 股和 $\mathrm{H}$ 股一年的股价收益率的波动率分别以其流通股数 与交易日数量加权得到股权市场价值的波动率，即
IV.KMV 的实证研究

根据之前股权市场价值的计算方法计算 $\mathrm{S}$, 再根据 （8）式计算 2018 全年的股权价值波动率, 确定的无风 险利率 $\mathrm{r}$ 以及违约点 DPT 和时间 $\mathrm{T}$, 结合 (2)、（3） 式利用软件 MATLAB.R2014a 设计 KMV 模型来度量商 业银行信用风险。

将以上的得到程序结果按照负债违约距离以升序即 违约概率以降序排列,结果如表 2:

全年股权价值波动率 $=$

$\sqrt{\frac{\mathrm{A} \text { 股流通数量 } \times \mathrm{A} \text { 股交易日 }}{\mathrm{A} \text { 股流通数量 }+\mathrm{H} \text { 股流通数量 }} \times \text { 全年 } \mathrm{A} \text { 股股价收益率波动率 }}{ }^{2}+\frac{\mathrm{H} \text { 股流通数量 } \times \mathrm{H} \text { 股交易日 }}{\mathrm{A} \text { 股流通数量 }+\mathrm{H} \text { 股流通数量 }} \times$ 全年 $\mathrm{H}$ 股股价收益率波动率 $^{2}$

(8)

我们按照之前参数设定以及相关度量指标计算方法 得到商业银行违约点、股权市场价值、全年股权价值波 动率如表 1 :

表 1: 商业银行违约点、股权市场价值、全年股权价值波动率

\begin{tabular}{|c|c|c|c|}
\hline 银行名称 & $\begin{array}{l}\text { 违约点（万 } \\
\text { 元） }\end{array}$ & $\begin{array}{c}\text { 股权市场价值 } \\
\text { (万元） }\end{array}$ & $\begin{array}{c}\text { 全年股权价值 } \\
\text { 波动率 }\end{array}$ \\
\hline 无锡银行 & 7238604.5 & 1134564.327 & 0.340464404 \\
\hline 杭州银行 & 81415234 & 4747743.99 & 0.442044511 \\
\hline 上海银行 & 100465580 & 14294634.46 & 0.440966697 \\
\hline 张家港银行 & 5132671 & 1097451.446 & 0.480299114 \\
\hline 华夏银行 & 235899800 & 10584181.52 & 0.209673963 \\
\hline 贵阳银行 & 28686571 & 1294863.962 & 0.256629184 \\
\hline 江阴银行 & 5835254.5 & 1106970.736 & 0.366456915 \\
\hline 平安银行 & 179054300 & 18543362.72 & 0.332310503 \\
\hline 常熟银行 & 21575179 & 1353142.525 & 0.328889614 \\
\hline 民生银行 & 300132850 & 29754255.68 & 0.282292797 \\
\hline 宁波银行 & 61815986 & 8885710.495 & 0.306724125 \\
\hline 南京银行 & 71544745.5 & 6693817.506 & 0.265298561 \\
\hline 苏农银行 & 5645943 & 1046749.24 & 0.37254891 \\
\hline 光大银行 & 222928400 & 17854712.84 & 0.230124353 \\
\hline 中信银行 & 295420300 & 24871576.79 & 0.278181125 \\
\hline 建设银行 & 1124856300 & 154930856.7 & 0.265474674 \\
\hline 招商银行 & 321145150 & 72056826.08 & 0.305349281 \\
\hline 农业银行 & 1102976750 & 122378165.4 & 0.243041941 \\
\hline 工商银行 & 1349493350 & 201739837.7 & 0.255241452 \\
\hline 交通银行 & 441816650 & 41130330.73 & 0.200952909 \\
\hline 浦发银行 & 320859750 & 1809315.585 & 0.214813107 \\
\hline 江苏银行 & 108112475 & 8872465.795 & 0.189773447 \\
\hline 兴业银行 & 340069150 & 34214101.06 & 0.208518046 \\
\hline 中国银行 & 1017289250 & 106966183.2 & 0.207154068 \\
\hline 北京银行 & 98464300 & 14024726.6 & 0.179052442 \\
\hline
\end{tabular}

表 2.KMV 模型度量结果

\begin{tabular}{|c|c|c|c|c|}
\hline $\begin{array}{l}\text { 银行 } \\
\text { 名称 }\end{array}$ & $\begin{array}{l}\text { 资产价值市场 } \\
\text { 价值（万元） }\end{array}$ & $\begin{array}{l}\text { 价值波动 } \\
\text { 率 }\end{array}$ & $\begin{array}{l}\text { 负债违约 } \\
\text { 距离 }\end{array}$ & 违约概率 \\
\hline 无锡银行 & 72443000 & 0.0053 & 0.1466 & 0.4417 \\
\hline 杭州银行 & 141670000 & 0.015 & 1. 2578 & 0.1042 \\
\hline 上海银行 & 181270000 & 0.0351 & 1. 8469 & 0.0324 \\
\hline 张家港行 & 6151700 & 0.0866 & 1. 9131 & 0.0279 \\
\hline 华夏银行 & 418980000 & 0.0053 & 1.9881 & 0.0234 \\
\hline 贵阳银行 & 41434000 & 0.008 & 2. 0711 & 0.0192 \\
\hline 江阴银行 & 20043000 & 0.3145 & 2. 2539 & 0.0121 \\
\hline 平安银行 & 311840000 & 0.0198 & 2.2875 & 0.0111 \\
\hline 常熟银行 & 21438000 & 0.0208 & 2. 3563 & 0.0092 \\
\hline 民生银行 & 535160000 & 0.0157 & 2. 6327 & 0.0042 \\
\hline 宁波银行 & 98449000 & 0.0277 & 2. 7627 & 0.0029 \\
\hline 南京银行 & 110800000 & 0.016 & 2.8832 & 0.002 \\
\hline 苏农银行 & 16209000 & 0.2236 & 2.914 & 0.0018 \\
\hline 光大银行 & 395280000 & 0.0104 & 2.9572 & 0.0016 \\
\hline 中信银行 & 315890000 & 0.0219 & 2. 9588 & 0.0015 \\
\hline 建设银行 & 2211300000 & 0.0186 & 3. 0111 & 0.0013 \\
\hline 招商银行 & 388420000 & 0.0567 & 3. 0572 & 0.0011 \\
\hline 农业银行 & 2148600000 & 0.0138 & 3. 0849 & 0.001 \\
\hline 工商银行 & 2655200000 & 0.0194 & 3. 1977 & 0.00069 \\
\hline 交通银行 & 847910000 & 0.0097 & 3.5011 & 0.00023 \\
\hline 浦发银行 & 546680000 & 0.0129 & 3.5505 & 0.00019 \\
\hline 江苏银行 & 170990000 & 0.0098 & 3. 8143 & 0.00006 \\
\hline 兴业银行 & 369220000 & 0.0193 & 4. 0861 & 0.00002 \\
\hline 中国银行 & 1109100000 & 0.02 & 4. 1438 & 0.00001 \\
\hline 北京银行 & 201190000 & 0.0125 & 4. 4585 & 0.000004 \\
\hline
\end{tabular}

根据理论 KMV 模型, 当公司的违约距离越低, 违 约概率越高, 暴露的风险头寸越大。以上表数据得出, 表中实证结果与 KMV 理论模型所预期的结果一致。 
我们根据违约概率与标准普尔、穆迪信用评级等级 之间对应关系,如表 3:

表 3.违约概率与评级等级对应关系

\begin{tabular}{ccc}
\hline 违约概率 & 标准普尔 & 穆迪 \\
\hline $0.02-0.04$ & $\geq \mathrm{AA}$ & $\geq \mathrm{Aa} 2$ \\
$0.04-0.10$ & $\mathrm{AA} / \mathrm{A}$ & $\mathrm{A} 1$ \\
$0.10-0.19$ & $\mathrm{~A} / \mathrm{BBB}+$ & $\mathrm{Baa} 1$ \\
$0.19-0.40$ & $\mathrm{BBB}+/ \mathrm{BBB}-$ & $\mathrm{Baa} 3$ \\
$0.40-0.72$ & $\mathrm{BBB}-/ \mathrm{BB}$ & $\mathrm{Ba} 1$ \\
$0.72-1.01$ & $\mathrm{BB} / \mathrm{BB}-$ & $\mathrm{Ba} 3$ \\
$1.01-1.43$ & $\mathrm{BB}-/ \mathrm{B}+$ & $\mathrm{B} 1$ \\
$1.43-2.02$ & $\mathrm{~B}+/ \mathrm{B}$ & $\mathrm{B} 2$ \\
$2.02-3.45$ & $\mathrm{~B} / \mathrm{B}-$ & $\mathrm{B} 3$
\end{tabular}

将所度量的商业银行进行评级, 结果: 在 2018 年中, 北京、中国、兴业、江苏、浦发、交通、工商、农业、 招商、建设、中信、光大、苏农、南京、宁波、民生、 常熟、平安、江阴、贵阳银行标准普尔评级为 $\geq \mathrm{AA}$, 穆 迪评级为 $\geq \mathrm{Aa} 2$; 华夏、张家港、上海银行标准普尔评级 为 $\mathrm{AA} / \mathrm{A}$, 穆迪评级为 $\mathrm{A} 1$; 杭州银行标准普尔评级为 $\mathrm{A} / \mathrm{BBB}+$, 穆迪评级为 $\mathrm{Baa} 1$; 无锡银行标准普尔等级为 $\mathrm{BBB}-/ \mathrm{BB}$, 穆迪评级为 $\mathrm{Ba} 1$; 从表中我们可以看出, 在 2018 年中, 大多数商业银行信用风险比较稳定, 杭州银 行暴露的风险头寸较小, 无锡银行暴露较大的风险头寸。

\section{$\mathrm{V}$.结论与讨论}

本文借鉴 KMV 模型度量 2018 年 25 家商业银行的信用 风险, 结果发现: 25 家大部分商业银行信用风险较低;

无锡银行暴露的风险头寸较大; 杭州银行其次。 按照标准普尔、穆迪信用评级与违约概率所对应的关系, 得到: 在 2018 年中, 北京、中国、兴业、江苏、浦发、 交通、工商、农业、招商、建设、中信、光大、苏农、 南京、宁波、民生、常熟、平安、江阴、贵阳银行标准 普尔评级为 $\mathrm{AAA}$, 穆迪评级为 $\mathrm{Aa} 2$; 华夏、张家港、 上海银行标准普尔评级为 $\mathrm{AA} / \mathrm{A}$, 穆迪评级为 $\mathrm{A} 1$; 杭州 银行标准普尔评级为 $\mathrm{A} / \mathrm{BBB}+$, 穆迪评级为 $\mathrm{Ba} a 1$; 无锡

银行标准普尔等级为 BBB-/BB, 穆迪评级为 $\mathrm{Ba}$ 。 对策建议:

1、银行应根据我国具体国情以及符合自身企业情况, 建立符合银行内部的信用评级系统, 形成信用评级体系, 以便于能更好对自身以及相关贷款企业的信用评级做出 有效评估，控制不良贷款的数量，防范信用风险。
2、随着中国信用产品市场不断成熟, 银行应引进和培 养具有熟悉西方现代信用风险管理方法, 熟悉信用风险 度量模型, 能够定量分析信用分析, 懂得利用金融工程 管理信用风险的科学专业信用风险管理人才, 以便于能 够更好的规避信用风险。

3、银行通过人才的引进与培养, 在符合具体国情和银 行自身相关情况, 进行信用风险度量和模型改进, 建立 和完善信用风险基础数据库。

\section{致谢}

本研究得到云南省科技计划面上项目《云南省小微 金融机构信贷风险预警机制研究》(2017FB103)的大力 资助。

\section{参考文献}

[1] 刘向华,李林娜, “基于 KMV-GARCH-t-copula 模型的上市公司 BDS 定价研究”, 统计与决策,pp:162-165,2015.

[2] 蒋书涁, “基于 KMV 动态违约距离的商业银行信用风险研究”, 金融与经济,pp:61-65+27,2016.

[3] 谢赤,王彭,杨姣姣,王纲金, “基于 DCC-MSV-KMV 模型的第三产 业行业信用风险传染效应度量”, 湖南大学学报(自然科学 版),pp:111-116, 2013.

[4] 王秀国,谢幽筀, “基于 $\mathrm{CVaR}$ 和 $\operatorname{GARCH}(1,1)$ 的扩展 $\mathrm{KMV}$ 模型” , 系统工程,pp:26,2012.

[5] 李杰汀, “基于传染病模型的企业集团内部信用风险传染研究”, 中国灾害防御协会风险分析专业委员会第三届年会论文集,pp: 56-61,2013

[6] 徐蕾,刘小川, “地方政府债务违约风险测度”, 上海经济研究, pp:84-93,2018.

[7] 徐占东,王雪标, “中国省级政府债务风险测度与分析”, 数量经济 技术经济研究, pp:38-54,2014.

[8] 李晟, 张宇航, “中国上市商业银行信用风险分析及比较一一基于 KMV 模型及面板数据”,中央财经大学学报, pp:31-38,2016.

[9] 张玲,杨贞柿, “陈收.KMV 模型在上市公司信用风险评价中的应 用研究”,系统工程,pp:84-89,2004.

[10] 蒋或, 高瑜, “基于 KMV 模型的中国上市公司信用风险评估研 究”,中央财经大学学报, pp:38-45,2015.

[11] 唐振鹏,陈尾虹, 黄友珀, “上市公司信用风险的度量”, 统计与决 策,pp:174-179,2016.

[12] 曾诗鸿,王芳, “基于 KMV 模型的制造业上市公司信用风险评价 研究”,预测, pp:60-63+69,2013.

[13] 徐朝辉, “税制改革与公司信用风险研究”, 中国灾害防御协会风 险分析专业委员会第三届年会论文集,pp:37-43,2013.

[14] 戴志锋,张宗益,陈银忠, “基于期权定价理论的中国非上市公司信 用风险度量研究”,管理科学,pp:72-77,2005.

[15] 韩娇, “我国商业银行信用风险评价应用研究, 首都经济贸易大 学”,2018. 